\title{
PERAN PENDAMPINGAN REGULASI EMOSI TERHADAP PERILAKU MALTREATMENT PADA IBU DARI ANAK GPP/H
}

\author{
Erny Hidayati \\ Fakultas Psikologi Universitas Ahmad Dahlan \\ Jl. Kapas No 9, Semaki Yogyakarta \\ ernypsiuad@yahoo.com
}

\begin{abstract}
This study was aimed to examine the role of emotion regulation assistance to decrease of physical maltreatment behavior, namely pinching behavior on mothers of ADHD children. This research was used within subject design with $\mathrm{ABAB}$ single subject design. There were two mothers of ADHD children participating in this study. They were clients of The Assessment Center for Child Growth and Development in Yogyakarta. Data were obtained from self monitoring note and reflection of experience during emotion regulation assistance study period was going on. Data were analyzed by using visual inspection. Data of subject reflection during assistance period were analyzed qualitatively using content analysis approach. The result showed that emotion regulation assistance evoked the change of awareness on both subjects. The new awareness influenced the way of the subjects to view behavior of ADHD children. Furthermore this influenced on decreasing physical maltreatment behavior, namely pinching behavior monitored.
\end{abstract}

Keyword: ADHD, physical maltreatment, regulation emotion assistance

\begin{abstract}
Abstrak
Penelitian ini bertujuan menguji peran pendampingan regulasi emosi dalam menurunkan perilaku maltreatment fisik yaitu perilaku mencubit pada ibu yang memiliki anak dengan Gangguan Pemusatan Perhatian / Hiperaktivitas (GPPH). Rancangan penelitian yang digunakan adalah within subject dengan model rancangan $A B A B$ single subject design. Jumlah subjek dalam penelitian ini 2 orang ibu yang memiliki anak dengan GPP/H yang menjadi pasien di Pusat Pengkajian dan Pengamatan Tumbuh Kembang Anak Yogyakarta. Data diperoleh dari catatan pemantauan diri
\end{abstract}


dan refleksi pengalaman selama masa penelitian pendampingan regulasi emosi berlangsung. Data dianalisis dengan inspeksi visual. Data refleksi subjek selama masa pendampingan dianalisis secara kualitatif dengan pendekatan analisis isi. Hasil menunjukkan bahwa pendampingan regulasi emosi menimbulkan perubahan kesadaran pada kedua subjek. Kesadaran baru tersebut mempengaruhi cara kedua subjek dalam memandang perilaku anak GPP/H dan selanjutnya berpengaruh terhadap penurunan perilaku maltreatment fisik yaitu perilaku mencubit yang dipantau.

Kata Kunci : GPP/H, pendampingan regulasi emosi, perilaku maltretament fisik

\section{Pendahuluan}

Gangguan Pemusatan Perhatian / Hiperaktivitas biasa disingkat GPP/H atau Attention Deficit Hyperactivity Disorder disingkat ADHD adalah suatu kelainan neurobiologis yang biasanya bercirikan ketidakmampuan dalam memusatkan perhatian (inattention), mudah beralih perhatiannya (impulsivity) dan hiperaktivitas (CH.A. D. D., 1994). Menurut APA(1994) ciri mendasar dari GPP/H adalah pola inatensi yang dapat disertai atau tidak disertai hiperaktif-impulsif yang permanen. GPP/H dapat lebih berat dibandingkan dengan tingkat perkembangannya. GPP/H dibagi menjadi 3 subtipe yaitu: tipe predominan tidak adanya perhatian, tipe predominan hiperaktif/impulsif, dan tipe kombinasi yang ditandai dengan tidak adanya perhatian dan hiperaktivitas-impulsivitas tingkat tinggi.

Maslim (2001) menyebut GPP/H sebagai Gangguan Hiperkinetik. Ciri utama ialah berkurangnya perhatian dengan aktivitas berlebihan, kedua ciri ini mejadi syarat mutlak untuk diagnosis dan haruslah nyata ada pada lebih dari satu situasi (misalnya di rumah, di kelas, di klinik). Berkurangnya perhatian tampak jelas dari terlalu dini dihentikannya tugas dan ditinggalkannya suatu kegiatan sebelum tuntas selesai. Kehilangan minat terhadap tugas yang satu karena perhatiannya tertarik pada kegiatan lainnya. Hiperaktivitas dinyatakan dalam kegelisahan yang berlebihan, khususnya dalam situasi yang menuntut keadaan relatif tenang.

Anak dengan GPP/H juga akan mengalami kesulitan belajar misalnya kesulitan dalam membaca atau berhitung, biasanya tampak pada usia pra sekolah. Anak GPP/ H mengalami kesulitan dalam perencanaan, mengatur perilakunya dan regulasi diri, kesulitan lainnya meliputi memori, komunikasi, emosi serta keterampilan sosial (Nelson 
\& Israel, 2006). Penelitian Crundwell (2005) menunjukkan bahwa anak yang mengalami GPP/H disertai gejala Hiperaktivitas dan Impulsivitas sulit mengendalikan diri dan mengalami hambatan emosional. Banyak perilaku yang tak terduga seperti: temper tantrum, dan suasana hati yang berubah-ubah dapat menyebabkan suasana hati yang buruk dan depresi (Flanagen, 2005). Anak-anak dengan GPP/H pada umumnya sangat keras kepala dan impulsif, ketika tidak mendapatkan sesuatu yang diinginkan biasanya menjadi marah dan temper tantrum. Beberapa anak tidak empatik, mengalami gejala seperti berubah-ubahnya suasana hati, kegelisahan, sering meledakan amarah dan tendensi untuk mengambil resiko yang tak perlu.

Menurut Flanagen (2005) kondisi yang demikian sering membuat orangtua khususnya ibu kelelahan karena berusaha mengatasi perilaku anak-anak mereka, dan mendekati depresi setelah mengetahui bahwa anaknya mengalami GPP/H. Orangtua menjadi cemas, merasa kecewa dan biasanya bersikap menuntut atau menekan anak, lebih banyak mencela dan kurang memberikan penghargaan bahkan juga marah (Wells, Epstein, Hinshaw, dan Conners, 2000).

Kondisi tersebut seringkali menyebabkan ibu menjadi kurang sabar. Ibu merasa frustrasi dan jengkel dengan perilaku anak GPP/H. Kekesalan tersebut tidak jarang dilampiaskannya dengan berlaku kasar, sering menghukum bahkan memukul, lebih mengontrol, berespon lebih negatif, lebih banyak perintah dan larangan, serta memberikan sedikit respon terhadap permintaan perhatian anak dengan GPP/H dibandingkan dengan anak lainnya (Ingersoll, 1988). Ibu yang memiliki anak hiperaktif juga bersikap lebih negatif dan direktif daripada ibu yang anaknya tidak mengalami hiperaktif (Keown \& Woodward, 2002). Situasi tersebut menunjukkan adanya indikasi terjadinya perilaku maltreatment pada ibu yang memiliki anak dengan GPP/ H. Perilaku maltreatment adalah suatu kategori umum yang meliputi semua situasi dimana orangtua atau orang lain yang mestinya bertanggungjawab terhadap kesejahteraan anak melakukan kekerasan atau mengabaikan kebutuhan anak (Cook \& Cook, 2005).

Menurut Gelles (2005), maltreatment pada anak adalah tindakan yang secara sengaja membahayakan anak, baik secara fisik maupun emosional. Istilah maltreatment pada anak meliputi perilaku penganiayaan fisik dari orangtua atau orang dewasa lain yang bertugas mengasuhnya sampai pada penelantaran kebutuhan dasar anak.

Data yang diperoleh dari hasil preliminary study yang dilakukan, menunjukkan bahwa hasil dari wawancara dengan ibu yang memiliki anak terdiagnosa GPP/H menunjukkan bahwa ibu sering tidak sabar dan jengkel menghadapi perilaku anak 
yang tidak pernah dapat tenang, suka memporak porandakan mainan atau barangbarang yang ada di rumah, berguling-guling ketika keinginannya tidak terpenuhi. Sikap ibu menjadi lebih kasar dan terkadang “ringan tangan”, mencubit dan memukul, menyeret ketika anak tidak segera melakukan instruksi yang diberikan, ibu merasa anak merepotkannya. Sikap keras yang dilakukan oleh ibu dalam upaya mengendalikan perilaku anak, namun kenyataan justru sebaliknya, anak menjadi marah dan menunjukkan sikap melawan. Hal ini menunjukkan bahwa ibu yang memiliki anak dengan GPP/H merasa tertekan dan sering mengalami kesulitan ketika menghadapi perilaku dan emosi anaknya, dan terkadang ibu harus menahan emosinya sendiri ketika menghadapi perilaku anaknya.

Menurut Robin (1998), ibu sebagai orangtua diharapkan dapat bersikap lebih sabar, toleran, hangat, tenang dan konsisten dalam mengasuh anak dengan GPP/H. Kenyataan di atas menunjukkan sebaliknya, ibu justru terpengaruh dan menunjukkan emosi dan reaksi negatif. Interaksi ibu dan anak menjadi buruk. Interaksi ibu dan anak yang buruk secara terus menerus dapat memperburuk perilaku anak (Podolski \& Nigg, 2001). Penelitian Becker-Blease dan Freyd (2008) menemukan bahwa anak dengan GPP/H yang mengalami kekerasan, memiliki gejala impulsivitas dan inattention yang lebih parah dibandingkan dengan anak dengan GPP/H yang tidak mengalami kekerasan.

Berdasarkan permasalahan di atas maka perlu ada upaya yang dapat memberikan manfaat praktis dan segera dirasakan agar ibu tidak merasa tertekan sehingga menjadi lebih tenang dan sabar dalam menghadapi anak dengan GPP/H. Upaya yang bisa dilakukan antara lain dengan pendampingan pada ibu yang memiliki anak dengan GPP/H untuk mengatur emosinya atau melakukan regulasi emosi. Regulasi emosi perlu dilakukan ibu agar dapat melatih dan mengendalikan emosinya terutama selama berinteraksi dengan anak dengan GPP/H. Ibu dengan kemampuan regulasi emosi yang baik, diharapkan memiliki reaksi emosional yang positif.

Regulasi emosi adalah proses pengenalan, pemeliharaan dan pengaturan emosi positif maupun negatif, baik yang tampak maupun yang tersembunyi, baik disadari maupun tidak disadari (Gross, 2003). Greenberg (Hidayati, 2008). mendefinisikan regulasi emosi sebagai suatu proses untuk menilai, mengatasi, mengelola dan mengungkapkan emosi yang tepat dalam rangka mencapai keseimbangan emosional

Gross (2003) menyatakan ada dua model regulasi emosi dengan membedakan regulasi emosi ke dalam dua bentuk besar strategi regulasi emosi. Bentuk pertama Antecedence-Focused (Cognitive Reappraisal) yang terdiri dari empat aspek yaitu pemilihan situasi, modifikasi situasi, penyebaran perhatian dan perubahan kognitif. 
Bentuk kedua Response-Focused (Expressive Suppression ) yang merupakan modulasi respon. Pada proses antecedent-focused terjadi proses menilai kembali (cognitive reappraisal) terhadap situasi yang akan berdampak pada emosi. Menurut Lazarus (Strongman, 2003) proses ini bersifat evaluatif terhadap situasi yang dihadapi individu. Pada saat individu menilai situasi yang dihadapi bersifat negatif maka emosi yang dikembangkan oleh individu lebih bersifat negatif, sebaliknya bila individu menilai situasi yang dihadapi bersifat positif maka emosi yang dikembangkan cenderung bersifat positif. Berdasarkan penelitian yang dilakukan Gross \& John (2003) individu yang memilih strategi antecedent-focused / reappraisal mempunyai fungsi interpersonal dan kesejahteraan yang lebih baik. Hal ini didukung hasil penelitian Gross, Mauss, Cook, dan Cheng (2007) yang menemukan bahwa strategi reappraisal terbukti dapat menurunkan emosi marah. Pada proses response-focused, terjadi usaha untuk menekan ekspresi emosi (suppression). Strategi ini efektif untuk menurunkan ekspresi emosi negatif tetapi memberikan efek samping yaitu menekan ekspresi positif dan tidak membantu mengurangi pengalaman negatif (Gross dan John, 2003).

Pendampingan dalam penelitian ini dilakukan dengan memberikan informasi mengenai GPP/H dan kedua model proses regulasi emosi melalui kelima aspeknya (pemilihan situasi, modifikasi situasi, penyebaran perhatian, perubahan kognitif dan modulasi respon). Hal ini bertujuan untuk mengetahui informasi mengenai GPP/H dan beberapa cara regulasi emosi secara jelas, ibu lebih bisa mengelola emosi secara baik karena persepsi ibu yang semula negatif terhadap perilaku anak dengan GPP/H berubah lebih positif, ibu lebih memahami dinamika perilaku anak dengan GPP/H, lebih bisa menerima kondisi anak dan dapat memberikan pengasuhan yang lebih positif.

Berdasar berbagai informasi dan paparan teoritis di atas, maka dapat diajukan hipotesis sebagai berikut: pendampingan regulasi emosi menurunkan perilaku maltreatment fisik ibu terhadap anak dengan GPP/H.

\section{Metode Penelitian}

Subjek penelitian ini adalah ibu yang memiliki anak dengan GPP/H usia 3 sampai dengan 7 tahun yang terdiagnosa GPPH di Pusat Pengkajian dan Pengamatan Tumbuh Kembang Anak Yogyakarta. Subjek dalam penelitian ini berjumlah 2 orang. Rancangan penelitian yang digunakan dalam penelitian ini adalah within subject dengan model rancangan $A B A B$ single subject design. Menurut Jones, dkk. (Myers 
dan Hansen, 2002) subjek penelitian dalam desain within subject akan dihadapkan pada satu kondisi perlakuan, sehingga memungkinkan untuk membandingkan perilaku subjek yang sama dalam kondisi perlakuan dan kondisi tanpa perlakuan.

Model rancangan $\mathrm{ABAB}$ menghadapkan subjek pada dua kondisi perlakuan yang dihadirkan secara berulang yaitu kondisi tanpa perlakuan atau baseline (dinotasikan dengan A) dan kondisi dengan perlakuan (dinotasikan dengan B), sehingga penelitian ini dimulai dari fase baseline satu, diikuti fase perlakuan satu, kembali ke fase baseline dua (kondisi tanpa perlakuan) dan ditutup dengan fase perlakuan dua.

\begin{tabular}{|lllll|}
\hline \multirow{5}{*}{ Single subject } & $\mathrm{A}$ & $\mathrm{B}$ & $\mathrm{A}$ & $\mathrm{B}$ \\
& Baseline & Perlakuan & Baseline & Perlakuan \\
& $-\mathrm{X}$ & $\mathrm{X}$ & $-\mathrm{X}$ & $\mathrm{X}$ \\
& $\mathrm{O} 1$ & $\mathrm{O} 2$ & $\mathrm{O} 3$ & $\mathrm{O} 4$ \\
\hline
\end{tabular}

Gambar 1. Rancangan Penelitian ABAB Single-subject design

Keterangan :

$\mathrm{X}$ : Administrasi variabel bebas dalam penelitian berupa perlakuan dengan pendampingan dalam regulasi emosi

$\mathrm{O}$ : Variabel tergantung dalam penelitian berupa perilaku maltreatment ibu

O1 dan O3 : perilaku maltreatment ibu dalam fase tanpa perlakuan

$\mathrm{O} 2$ dan $\mathrm{O} 4$ : perilaku maltreatment ibu dalam fase perlakuan

Metode pengambilan data yang digunakan pada penelitian ini adalah wawancara, self-monitoring atau pemantauan diri yang dilakukan oleh subjek serta refleksi pengalaman subjek.

\section{Wawancara}

Penggunaan wawancara pada penelitian ini bertujuan untuk memperoleh data awal tentang perilaku target yang ingin dilihat dan diukur, yaitu perilaku maltreatment fisik yang dilakukan ibu terhadap anak dengan GPP/H dann emosi negatif yang dirasakan ibu akibat situasi atau perilaku anak dengan GPP/H yang dirasakan ibu sulit dikendalikan untuk menetapkan baseline sebelum diberikan pendampingan regulasi emosi. Pada penelitian ini wawancara juga dilakukan pada saat pendampingan. Wawancara yang dilakukan adalah wawancara 
terapiutik yaitu suatu proses wawancara yang dilakukan dengan penuh penerimaan dan empati, tidak sekedar mencari informasi atau data yang berkaitan dengan situasi dan emosi yang dirasakan subjek penelitian serta perilaku maltreatment fisik yang muncul, tetapi juga membantu subjek menemukan solusi dalam melakukan regulasi emosi agar tidak terjadi perilaku maltreatment fisik terhadap anak dengan GPP/H.

\section{Self-monitoring (pemantauan diri)}

Lembar pemantauan diri digunakan sebagai alat untuk merekam data perilaku target yang dilakukan oleh subjek penelitian, sehingga dapat diketahui adanya pola perubahan perilaku target dari fase sebelum diberikan pendampingan dengan fase sesudah diberikan pendampingan. Metode yang digunakan adalah pemantauan secara kontinyu (continuous recording) yang merupakan identifikasi kemunculan dan ketidakmunculan perilaku target yang dilakukan sepanjang periode penelitian. Pencatatan dalam penelitian ini berlangsung dari fase baseline satu sampai pada fase perlakuan dua. Dimensi perilaku target yang dicatat dalam penelitian ini adalah frekuensi kemunculan perilaku maltreatment fisik yang dilakukan ibu terhadap anak dengan GPP/H setiap hari mulai dari fase baseline satu sampai fase perlakuan dua.

\section{Refleksi pengalaman subjek}

Refleksi pengalaman subjek selama proses pendampingan dan selama program penelitian berlangsung bertujuan untuk memberikan umpan balik langsung pada subjek dalam menjalani perubahan yang dialaminya.

Prosedur penelitian terbagi dalam dua tahap yaitu :

1. Tahap Persiapan

Beberapa aktivitas yang dilakukan dalam rangka mempersiapkan penelitian antara lain :

a. Melakukan studi pendahuluan untuk menindak lanjuti hasil kajian pustaka dan penelitian ilmiah dengan teknik wawancara

b. Penyusunan pedoman wawancara dalam pendampingan dan alat bantu

c. Penentuan pelaksana penelitian

d. Penjelasan pelaksanaan penelitian kepada pelaksana penelitian dari peneliti tentang program dan proses pendampingan secara umum dan diskusi tentang GPP/H serta regulasi emosi

e. Penentuan calon subjek penelitian : penentuan subjek penelitian dilakukan atas rekomendasi psikolog di Pusat Pengkajian dan Pengamatan Tumbuh 
Kembang Anak yang sesuai dengan kriteria subjek penelitian.

2. Pelaksanaan Penelitian

Pelaksanaan penelitian diawali dengan melakukan wawancara terhadap dua orang ibu yang memiliki anak terdiagnosa GPP/H yang direkomendasikan oleh psikolog P3TKA yang sesuai dengan kriteria subjek penelitian. Wawancara dilakukan oleh peneliti bertujuan untuk menentukan perilaku target yang berkaitan dengan emosi yang dirasakan mengganggu dan perilaku maltreatment fisik yang dilakukan oleh subjek penelitian. Perilaku maltreatment fisik sebagai perilaku target yang menjadi variabel tergantung ditentukan berdasarkan gejala dan perilaku yang muncul dalam waktu sebulan terakhir sebelum wawancara dilakukan. Hasil konfirmasi diputuskan bahwa perilaku maltreatment fisik yang akan diamati untuk kedua subjek adalah mencubit. Pelaksanaan penelitian bagi kedua subjek dilakukan secara terpisah karena kesulitan menemukan waktu yang sama bagi kedua subjek.

Data yang diperoleh dalam penelitian ini dianalisis melalui dua cara :

1. Data yang diperoleh dari pemantauan diri subjek dianalisis melalui inspeksi visual untuk melihat kecenderungan perubahan perilaku subjek dari fase baseline satu sampai fase perlakuan dua.

2. Dinamika proses perubahan yang terjadi pada subjek dilihat dari data yang diperoleh dari proses refleksi subjek dan wawancara selama proses pendampingan. Data tersebut dianalisis secara kualitatif dengan menggunakan analisis isi yaitu teknik yang digunakan untuk menarik kesimpulan dengan menemukan pesan, dan dilakukan secara objektif dan sistematis (Holsti dalam Moleong, 2001).

\section{Hasil dan Pembahasan}

1. Hasil Analisis Data Subjek A1

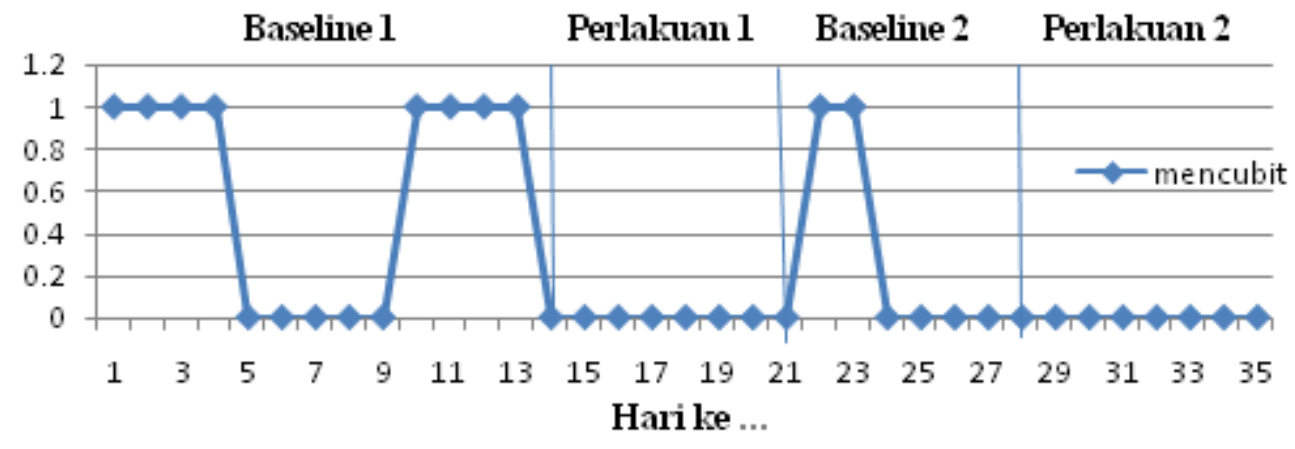

Grafik 1. Perilaku Mencubit Subjek A1 
Grafik pemantauan diri dalam perilaku mencubit pada Subjek A1 menunjukkan pada fase baseline satu (tanpa perlakuan satu), muncul berturutturut pada empat hari pertama, setelah itu lima hari tidak muncul , tetapi pada empat hari terakhir fase baseline satu perilaku mencubit ini kembali muncul setiap hari. Pada fase perlakuan satu terjadi penurunan perilaku mencubit tetapi muncul kembali pada hari pertama dan hari kedua fase tanpa perlakuan dua, selanjutnya tidak muncul kembali sampai fase perlakuan dua berakhir.

\section{Hasil Analisis Data Subjek A}

\section{mencubit}

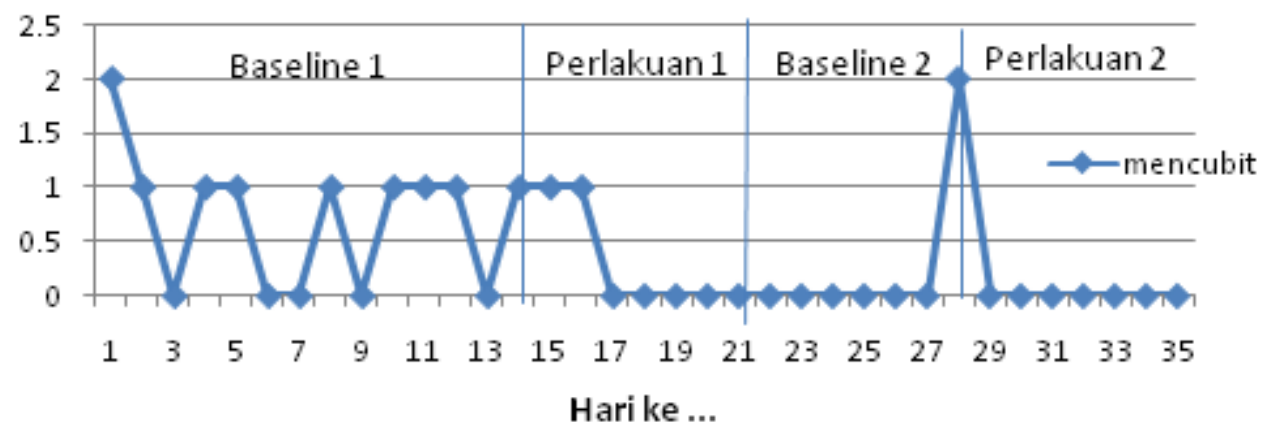

Grafik 2. Perilaku Mencubit Subjek A2

Grafik pemantauan diri dalam perilaku mencubit pada Subjek A2 menunjukkan pada fase baseline satu (tanpa perlakuan satu), hampir setiap hari muncul. Pada fase perlakuan satu perilaku mencubit muncul pada hari pertama dan kedua, selanjutnya terjadi penurunan perilaku mencubit tetapi muncul kembali pada hari ketujuh fase tanpa perlakuan dua, selanjutnya tidak muncul kembali sampai fase perlakuan dua berakhir.

Dari hasil inspeksi visual dapat terlihat bahwa terjadi penurunan pada perilaku mencubit pada kedua subjek setelah mendapatkan pendampingan regulasi emosi. Hal ini menunjukkan bahwa hipotesis dalam penelitian ini diterima.

Pendampingan regulasi emosi pada penelitian ini mengacu pada teori regulasi emosi yang dikemukakan oleh Gross dan John (2003), yang membedakan regulasi emosi ke dalam dua bentuk besar strategi regulasi emosi, yaitu Antecedence-Focused (Cognitive Reappraisal) yang terdiri dari empat aspek yaitu pemilihan situasi, modifikasi situasi, penyebaran perhatian dan perubahan kognitif dan Response- 
Focused.(Expressive Suppression ) yang merupakan modulasi respon.

Perubahan perilaku subjek dapat dijelaskan melalui kelima model proses regulasi emosi. Subjek berada pada situasi yang akan memunculkan emosi akibat perilaku anak dengan GPP/H yang sulit dikendalikan, subjek dapat melakukan regulasi emosi dengan pemilihan situasi dan modifikasi situasi antara lain dengan cara menyerahkan pengasuhan anak kepada suami dan memilih melakukan aktivitas lain, agar tidak terjadi interaksi yang lebih intens dengan anak untuk mencegah munculnya emosi negatif. Sebagaimana pendapat Gross dan Thompson (2007) yang menyatakan bahwa agar individu sampai pada situasi yang diharapkan, yang bisa menyebabkan emosi yang menyenangkan atau tidak menyenangkan, maka tindakan yang dapat dilakukan antara lain mendekati atau menghindari orang atau situasi yang dapat dilakukan sendiri atau dengan bantuan orang lain, agar dampak emosionalnya teralihkan. Model regulasi emosi pemilihan situasi dan modifikasi situasi seringkali memerlukan perspektif orang lain, mulai dari teman, orangtua sampai terapis (Gross \& Thompson, 2007). Tahap selanjutnya agar emosi negatif tidak muncul ketika anak dengan GPP/H menunjukkan perilaku tidak terkendali, subjek dapat melakukan regulasi emosi dengan cara penyebaran perhatian (attentional deployment) dan perubahan kognitif (cognitive change), misalnya ketika muncul perilaku anak dengan GPP/H yang sulit dikendalikan subjek dapat memusatkan perhatian dan berusaha mencari tahu penyebab dari perilaku tidak terkendali tersebut, bukan pada efek dari perilaku tidak terkendalinya, dan memaknai perilaku tidak terkendali tersebut sebagai perilaku yang tidak disengaja oleh anak, bahwa perilaku tersebut bukan kemauan anak melainkan akibat dari GPP/H yang disandangnya. Emosi negatif subjek tidak muncul ketika subjek memusatkan perhatian pada penyebab bukan pada efek dari perilaku tidak terkendali dan merubah persepsi terhadap perilaku anak maka, sehingga subjek menjadi lebih sabar dan tenang dalam menghadapi anak. Attentional deployment merupakan cara bagaimana individu mengarahkan perhatiannya di dalam sebuah situasi untuk mengatur emosinya, dan digunakan terutama ketika tidak mungkin mengubah atau memodifikasi situasi misalnya individu dapat mengalihkan pandangannya dari stimulus yang dapat menimbulkan emosi ke stimulus yang kurang menimbulkan emosi (Rothbart \& Sheese, dalam Gross \& Thompson, 2007). Perubahan kognitif melibatkan perubahan makna sebuah situasi dengan cara mengubah dampak emosionalnya, mengarahkan subjek untuk melakukan reappraisal terhadap situasi yang divalensi negatif ditemukan dapat menurunkan pengalaman emosi negatif. (Gross, 1998a; Steptoe \& Vogele dalam Gross \& Thompson, 2007). Emosi negatif yang sudah terlanjur muncul pada saat subjek menghadapi perilaku anak dengan 
GPP/H yang tidak terkendali, subjek dapat menggunakan modulasi respon untuk menghambat keluaran emosi dengan melakukan relaksasi pernafasan. Modulasi respon terjadi lebih kemudian di dalam proses pembangkitan emosi, yaitu setelah kecenderungan respon diinisiasi. Modulasi respon berpengaruh pada respon fisiologis, pengalaman, atau perilaku pada saat itu juga. Olahraga dan relaksasi dapat digunakan untuk mengurangi aspek-aspek fisiologis dan pengalaman emosi negatif (Gross \& Thompson, 2007).

Penelitian ini menunjukkan bahwa kedua subjek menggunakan kedua model strategi regulasi emosi yaitu strategi reappraisal (antecedent-focused) dan strategi Response-Focused (Expressive Suppression ) yang disesuaikan dengan situasi, namun lebih sering menggunakan strategi Response-Focused.(Expressive Suppression ) yaitu modulasi respon ketika emosi negatif sudah terlanjur muncul. Kedua subjek sering melakukan regulasi emosi dengan cara menghambat munculnya emosi negatif dengan cara diam sejenak dan melakukan relaksasi pernafasan ketika merasa jengkel atau marah akibat perilaku anak. Subyek merasakan perubahan pada saat subyek melakukan relaksasi, yaitu subjek merasa nyaman, rileks, dan tenang. Selama ini subjek mengalami ketegangan fisik ketika merasa marah dan jengkel dengan perilaku anak, tetapi setelah memperoleh ketrampilan relaksasi, subjek dapat mengelola ketegangan fisik yang dirasakan dan merasa lebih tenang. Hasil penelitian Nitkowski, Petermann, Buttner, Krause Leipoldt, dan Petermann (2009) sebelumnya juga membuktikan bahwa teknik relaksasi yang digunakan pada anak agresif mampu mengajarkan anak untuk fokus dan perhatian terhadap sumber masalah yang dapat memunculkan perilaku agresif. Subyek yang melakukan relaksasi dapat mengidentifikasi sumber masalah dan melakukan perilaku yang tepat terhadap masalah tersebut.

Hasil penelitian ini juga menunjukkan bahwa kedua subjek dalam melakukan regulasi emosi, tanpa melalui seluruh proses atau tahap dari kelima model proses regulasi emosi. Kedua subyek pada saat berada dalam situasi yang akan memunculkan emosi akibat perilaku anak dengan GPP/H yang sulit dikendalikan dapat memilih model yang memungkinkan dilakukan saat itu. Hal ini sesuai pendapat Gross dan Thompson (2007) yang menyatakan bahwa sebagai suatu strategi, kelima model proses regulasi emosi dapat dilakukan tanpa melalui seluruh proses atau tahap, misalnya dalam suatu siuasi yang akan memunculkan emosi, bisa saja seseorang tidak melakukan strategi situation selection atau situation modification, tetapi langsung melakukan attentional deployment.

Hasil refleksi diketahui bahwa strategi reappraisal (antecedent-focused) yang 
sering digunakan oleh subjek A1 adalah pemilihan situasi dan penyebaran perhatian. Cara pemilihan situasi dipilih oleh subjek ketika ada suami di rumah, subjek memilih menghindar dari anak dengan menyerahkan pengasuhan kepada suami, subjek memilih mengerjakan tugas yang lain, sehingga tidak terjadi interaksi yang intens yang dapat memicu emosi negatif. Subjek berusaha melakukan regulasi emosi dengan menggunakan cara penyebaran perhatian yaitu berusaha memusatkan perhatian untuk mencari tahu penyebab dari perilaku anak yang tidak terkendali ketika suami tidak berada di rumah. Emosi negatif subjek tidak muncul dan menjadi lebih sabar melayani anak pada saat subjek konsentrasi mencari tahu penyebab perilaku anak,

Pada subjek A2 setelah mengikuti pendampingan regulai emosi, mulai terjadi perubahan kognitif, terjadi perubahan penilaian terhadap perilaku anak. Subjek mulai menyadari bahwa perilaku anak yang sulit dikendalikan adalah akibat dari GPP/H yang disandangnya. Subjek juga melakukan perbandingan dengan anak lain yang juga memiliki kebutuhan khusus dan kondisinya lebih buruk dibandingkan kondisi anak. Kenyataan bahwa kondisi anak masih jauh lebih baik, menumbuhkan perasaan bersyukur pada subjek sehingga mengurangi munculnya emosi negatif seperti malu, jengkel, kesal dan marah. Hal ini didukung hasil penelitian Gross, Mauss, Cook, dan Cheng (2007) yang menemukan bahwa strategi reappraisal terbukti dapat menurunkan emosi marah.

Faktor yang mendukung keberhasilan pendampingan dalam penelitian ini adalah peran pendamping. Pengalaman, penguasaan materi, dan kualitas interpersonal yang baik merupakan modal utama yang mendukung pendamping dalam menjalankan pendampingan dengan baik. Pendamping mampu menumbuhkan suasana keterbukaan dan kedekatan dengan subjek. Faktor lain yang mendukung adalah partisipasi dari subjek juga mendukung keberhasilan dalam pendampingan. Subjek dalam pendampingan ini cukup kooperatif dan memperhatikan apa yang disampaikan oleh pendamping.

Keterbatasan dalam penelitian ini antara lain tidak dilakukannya pemantauan setelah pendampingan berakhir sehingga tidak diketahui secara kuantitatif seberapa besar efek pendampingan regulasi emosi dalam menurunkan perilaku maltreatment fisik khususnya perilaku mencubit yang dipantau.

\section{Simpulan}

Berdasarkan analisis data dan pembahasan hasil penelitian, diperoleh simpulan bahwa pendampingan regulasi emosi dapat menurunkan perilaku maltreatment fisik 
yaitu perilaku mencubit pada kedua subjek. Kedua subjek dalam penelitian ini menggunakan kedua model strategi regulasi emosi yaitu strategi reappraisal (antecedent-focused) dan strategi Response-Focused (Expressive Suppression ) tergantung situasi, namun lebih sering menggunakan strategi Response-Focused (Expressive Suppression).

\section{Daftar Pustaka}

American Psychiatric Association (1994). Diagnostic and Statistical Manual of Mental Disorder. (4 ${ }^{\text {th }}$, ed) Washington DC

Becker-Blease, K. A. \& Freyd J. J., (2008). A Preliminary Study of ADHD Symptoms and Correlates: Do Abused Children Differ from Nonabused Children? Journal of Aggression, Maltreatment \& Trauma, Vol. 17(1) \#51. http://jamt.haworthpress.com. Diakses 23 Januari 2010.

CH. A. D. D. Facts, (1994), Attention Deficit Disorder ; An Educator's Guide, Leaflet, Florida Plantation

Cook, J. L., \& Cook, G. (2005). Child development: Principles and perspectives (1st ed.) (p. 575). Boston: Allyn and Bacon.

Crundwell, R. M. A. (2005). An Initial Investigation of the Impact of Self Regulation and Emotionality on Behavior Problems in Children With ADHD. Canadian Journal of School Psychology. 20 (1-2). 62-74

Flanagen, R. (2005). ADHD Kids. Attention Deficit Hyperaction Disorder. Jakarta: Prestasi Pustaka Publisher.

Gellles, R.J. (2005). Child Abuse. Dalam Microsoft Encarta Encyclopedia. United States: Microsoft Corporation.

Gross, J.J. \& John, O.P. (2003). Individual Differences in Two Emotion Regulation Processes : Implications for Affect, Relationship and Well Being. Journal of Personality and Social Psychology, 85 (2), 348 - 362.

Gross, J. J. \& Thompson, R.A. (2007). Handbook of Emotion Regulation. Guilford Publications

Gross, J. J., Mauss, I. B., Cook, C. L., Cheng, J. Y. J., (2007). Individual differences in cognitive reappraisal: Experiential and physiological responses to an anger provocation. International Journal of Psychophysiology 43, 698711. 
Hidayati, Nazlah. 2008. Penanganan Stres Ibu-Ibu Korban Lumpur Panas Lapindo dengan Pelatihan Regulasi Emosi. Tesis. Tidak diterbitkan. Yogyakarta: Fakultas Psikologi UGM.

Ingersoll, B. (1988). Your Hyperactive Child. New York: Doubleday.

Keown, L. J \& Woodward, L. J. (2002). Early parent-child relations and family functioning of preschool boys with pervasive hyperactivity. Journal of Abnormal Child Psychology, 30(6), 541-553.

Maslim, R. (2001). Diagnosis Gangguan Jiwa : Rujukan Ringkas dari PPDGJIII. PT Nuh Jaya. Jakarta

Moleong, Lexy J. (2001). Metode Penelitian Kualitatif. Cetakan XIV. Jakarta : Remaja Rosdakarya.

Myers, A. \& Hansen, C.H. (2002), Experimental Psychology (5th ed). WadsworthThomson Learning, California, USA

Nelson, R. W \& Israel, A. C. (2006). Behavior Disorders of Childhood, sixth edition. New Jersey: Pearson Education, Inc.

Nitkowski, D., Petermann, F., Buttner, P., Krause Leipoldt, C., Petermann, U. (2009). Behavior Modification of Aggressive Children in Child Welfare Evaluation of a Combined Intervention Program. Behavior Modification, 33, 4, 474492.

Podolski, C. L \& Nigg, J. T. (2001). Parent stres and coping in relation to child ADHD severity and associated child disruptive behavior problem. Journal of Clinical Child Psychology, 30(4), 503-513.

Robin, A. L. (1998). ADHD in adolescents: Diagnosis and treatment. New York : Guilford Press.

Strongman, K.T. (2003). The Psychology of Emotion, From Everyday Life to Theory. $5^{\text {th }}$ edition. West Sussex : John Willey \& Sons Ltd.

Wells, K. C., Epstein, J. N., Hinshaw, S. P. \& Conners, K. C. (2000). Parenting and Family Stress Treatment Outcomes in Attention Deficit Hyperactivity Disorder (ADHD) : An Empirical Analysis in the MTA Study, Journal of Abnormal Child Psychology, (28), 543-553. 